\title{
Contemplation Ladder Readiness to Quit Smoking Likert Scale
}

National Cancer Institute

\section{Source}

National Cancer Institute. Contemplation Ladder Readiness to Quit Smoking Likert Scale. NCl Thesaurus. Code C124861.

A scale for the subjective scoring of readiness to quit smoking that ranges from $0: 1$ am not ready to quit to 10 : I am ready to quit now. 